\title{
Kernos
}

Revue internationale et pluridisciplinaire de religion grecque antique

3 | 1990

Varia

\section{Anna коғкоU, Crète. Tous les musées et les sites archéologiques}

\author{
Éveline Loucas-Durie
}

URL : http://journals.openedition.org/kernos/1030

DOI : $10.4000 /$ kernos. 1030

ISSN : 2034-7871

\section{Éditeur}

Centre international d'étude de la religion grecque antique

\section{Édition imprimée}

Date de publication : 1 janvier 1990

ISSN : 0776-3824

\section{Référence électronique}

Éveline Loucas-Durie, «Anna коғкоu, Crète. Tous les musées et les sites archéologiques », Kernos [En ligne], 3 | 1990, mis en ligne le 19 avril 2011, consulté le 22 septembre 2020. URL : http:// journals.openedition.org/kernos/1030; DOI : https://doi.org/10.4000/kernos.1030 
morphisme régnant justifie pleinement les qualités d'«anthropologue» attribuées à l'auteur grec! Les critiques des philosophes anciens, parmi lesquels Épicure reçoit un traitement de faveur, viennent adroitement donner à l'exposé une profondeur chronologique qui se referme sur les Pères de l'Église et leur Dieu créateur.

Cette lecture, qui est aussi réécriture, due à Giulia Sissa, éclaire le texte d'Homère d'un jour - et le terme convient ici dans ses deux acceptions ! - très agréable, même s'il n'est pas vraiment nouveau, et ce voyage au pays des dieux grecs ne dispensera de toute façon pas d'y suivre Homère en personne.

Dans la deuxième partie, Marcel Detienne pose la question de savoir ce que deviennent les Olympiens dans le temps des hommes. Sont-ils aussi envahissants dans la cité que dans l'épopée ? La réponse est mitigée : les dieux impliqués dans bon nombre des comportements du citoyen, certainement; des hommes assujettis aux puissances divines, assurément non. Le titre choisi est révélateur de ce point de vue : "Les dieux au plaisir de la cité», car s'ils règnent, ils ne gouvernent pas. Ce constat, jadis posé par L. Gernet et A. Boulanger, le tableau vivant, coloré et comme toujours très bien documenté du polythéisme de la Grèce des cités revu par Marcel Detienne, vient encore le confirmer. Et son exposé de s'achever sur la présentation du rôle de divinités féminines dans la formation des citoyens (Héra à Argos et Athéna à Athènes) et sur la mise en perspective d'un Dionysos - l'«enfant chéri» de l'A. ! - bel et bien présent dans la vie civique sous la forme d'un phallus, qui signifie l'élan de la force vitale et évoque, implicitement, la pérennité du groupe social.

Au total, un ouvrage plaisant, dont le style enlevé - émaillé de jeux de mots et d'expressions parfois surprenantes (p. 262: "Comme le train de nos passages à niveau, un phallus peut en cacher un autre») confirme le talent de nos auteurs pour «raconter» les derniers développements d'une discipline scientifique qui, sous leur plume, n'a plus rien d'austère! La vulgarisation atteint ici un très haut niveau, même si des esprits chagrins ne manqueront pas d'épingler les raccourcis inhérents à ce genre littéraire difficile.

Vinciane PIRENNE-DELFORGE

Anna KOFKOU, Crète. Tous les musées et les sites archéologiques, Athènes, Ekdotikè Athènon, 1989, 288 p., 358 ill. couleurs, 2 cartes, 24 x 17 $\mathrm{cm}$. (Traduction française due à $\mathrm{B}$. de Tournay).

Ce nouveau guide de Crète, magistralement illustré, retiendra l'attention de ceux qui s'intéressent aux croyances et aux pratiques religieuses crétoises. 
Outre un aperçu géographique et historique de l'île, l'A. consacre un chapitre intitulé «Les mythes de Crète» aux dieux et aux héros locaux, aux mythes de la naissance de Zeus, de son union avec Europe, au royaume de Minos, à Talos, et à l'art minoen. Des monuments figurés, utilisés en abondance pour illustrer les mythes exposés dans ce chapitre, un grand nombre proviennent de Crète même et sont peu connus.

Parmi les renseignements pratiques destinés au voyageur, on consultera avec profit l'agenda des manifestations culturelles qui mentionne les fêtes religieuses chrétiennes et les "panigyria" locaux; les 26 circuits proposés comptent presque tous des sites religieux préhistoriques ou historiques.

\section{Éveline LOUCAS-DURIE}

E.N. LANE, Corpus Cultus Iovis Sabazii, III, Conclusions, Leiden, Brill, 1989, 68 p., 2 tableaux, index (Études préliminaires aux religions orientales dans l'Empire romain, 100).

Ce bref tome conclut le Corpus Cultus Iovis Sabazii, travail que se sont partagé le regretté professeur Vermaseren et l'A. à qui l'on doit le recueil des textes littéraires et des monuments autres que les mains (CCIS II). Il nous donne ici un clair aperçu de nos connaissances sur le culte, avec une grande prudence qui frise même l'hypercritique.

Dans le premier chapitre (1-10), il dessine l'histoire du culte avant l'Empire romain, pour souligner qu'au début du Ier siècle, le culte fleurissait aussi en dehors de l'Anatolie, surtout en Thrace et en Campanie : l'A., qui n'aborde pas le (faux) problème de l'étymologie du nom et de l'origine thrace ou phrygienne du dieu, est un peu trop prudent dans l'utilisation des premiers témoignages, mais donne une bonne présentation des moments principaux de l'histoire hellénistique du culte (surtout son introduction officielle à Pergame, les sociétés de Sabaziastes dans le monde égéen, le temple thrace dont Alexandre Polyhistor se fait le témoin). Il étudie ensuite (11-22) le problème des divinités identifiées à Sabazios ou vénérées avec lui, pour souligner l'équivalence très répandue entre Sabazios et Zeus, et la forte relation entre Sabazios et Mercure. Dans un troisième chapitre (23-37), dédié aux symboles et aux formes du culte, il nous semble un peu abuser des rapprochements, plutôt superficiels, avec le culte chrétien. Le quatrième chapitre (38-48) ne réalise qu'en partie les promesses d'un titre séduisant (The cult in the Roman empire : who worshipped Sabazius and $w h y)$ : quelques aperçus statistiques, que serait venu compléter heureusement un exposé plus substantiel. Bon exposé du problème des variantes orthographiques du nom divin. Le cinquième chapitre (49-60) est dominé par la volonté d'expliquer toutes les notices qui rapprochent Sabazios et Dionysos, par rapport à la maigre documentation épigraphique, d'une tradition purement littéraire basée sur le fameux passage 